\title{
Women, Television and New Media - Engagement in the Makeover Culture
}

\author{
Aleksandra Powierska \\ Jagiellonian University, Poland \\ Email: aleksandra.powierska@uj.edu.pl
}

Doi:10.5901/mjss.2015.v6n2s2p19

\begin{abstract}
Among the most popular programs broadcasted by women's channels at present there are numerous makeover shows. Many researchers address them and analyze selected programs in the categories of reflexivity, governmentality (Sender 2012) or the culture of transparency, among others (Lisowska-Magdziarz 2012). However, at present television is not only the lineup but also the new media that accompany it and allow the viewers to comment on it. The aim of this article is to present to what extent the users of social media are engaged in the television narration taking place on the fanpage of a given channel as well as in what categories they speak of the programs, among which makeover shows are very popular. The basis of the research is the qualitative and quantitative analysis of posts and comments published on the official fanpage of the Polish women's television channel TVN Style. The research shows that in spite of the fact that, according to statistics, women are the most active users of social media, their transmedia engagement is relatively small. However, there are exceptions, which are extremely popular and whose interpretation reveals information on the internet users' worldview, the perception of television as an institution as well as the need to share one's own experiences.
\end{abstract}

Keywords: women's television, social media, makeover shows

\section{Introduction}

The contemporary television is not a single medium that can be described in a unitary category. Television has become a complex system requiring analysis on multiple levels. Among them the most important have become new media, which have changed not only the technology of broadcasting, but mainly the technology of reception of television. Television has become an interactive medium, oriented toward contact with the viewer, one that more and more often ceases to be a mass viewer. Program offers are personalized and channels aimed at viewers with specific interests emerge, because contact and the primacy of the target have pushed the lineup on to the back seat. Television has to be a good product that will satisfy the customer's needs - most preferably, on demand. Thus channels - alongside traditional broadcasting share their programs on VOD platforms or in social media. The internet has become an inseparable element of production and distribution of television content and paratexts accompanying it; in the age of the "meme culture" those frequently become more popular than the programs themselves. Some of them are created only with a view to the internet and the new viewer, the active user. This change is the sign of paratextualization of culture, about which Kazimierz Krzysztofek writes (2010), identifying macroconnectivity as one of its features. The notion refers to the theories of networks, which, to the author, "explain how, through a mighty decomposition of relationships, re- and multiplication (...) of the content occurs" [own translation - A.P.] (Krzysztofek 2010: 16). In this context, Krzysztofek (2010: 16) uses the notion of "overmedia" to describe the growing media system. The multiplication of content as well as places where the content is available make television a multilevel and polysemic system that cannot be considered without taking into account its new media environment. The new media, especially social media, have given viewers the voice and the possibility of expressing their opinions, commenting on or replying to the issues discussed by journalists. The phenomenon is especially visible in case of thematic channels. In the face of the above, one should take a closer look at them. The aim of this article is to find answers to the research questions below:

In what way do social media users speak of television programs?

Which content is the most interesting to them?

What does the abovementioned activity say about our culture?

The analysis is based on comments published on the official Facebook fanpage of "TVN Style" - Polish television station aimed at women. The choice of this station is supported by the fact that women are the most active group in social media - they spend 40\% more time using social media sites than men do (Michalska and Nowacka 2014). Hence the hypothesis that a station aimed at women, along with its internet environment, will generate much engagement on the 
part of the users. An important aspect is also the critical potential of comments by the viewers, frequently subversive in relation to the mainstream or unmasking the mechanisms of television creation and manipulation. The analysis of the messages shows also what social and political topics are currently important. However, before the interpretation of any specific broadcasts, one needs to provide some theoretical background and the most significant theories that have influenced the selection of the subject, the course of the research process as well as the formulation of the final conclusions.

\title{
2. Literature Review
}

The development of women's television took place in the 1990s, when a number of soap operas, in which the main roles were played by women, appeared (Lotz 2006). Amanda Lotz states that it was at that time that women became the target of media producers:

\begin{abstract}
"The expansion of sex-specific niche-audience targeting from cable to broadcast networks illustrates the importance of female audiences, a crucial target of industries now defined by media convergence and corporate conglomeration. Broadcast and cable networks enact intricate program selection and marketing strategies to acknowledge the variation among tastes and ideologies of different groups of women" (Lotz 2006: 7).
\end{abstract}

In Poland similar changes occurred almost a decade later. "TVN Style" is part of a media group named ITI Group, founded in 2004. From the very beginning the channel has been aimed at women and it has addressed topics such as fashion, beauty, cooking, family or health. The lineup is largely based on foreign programs and television formats, among which at present cooking and makeover shows dominate. In the lineup there is also place for talk shows, where the most popular is "The Social Mangle" (original title: "Magiel towarzyski") on show business and "The City of Women" ("Miasto kobiet") - a program addressing social issues, frequently concerned with women's rights. It is worth emphasizing that both the station as well as selected programs have their profiles on Facebook, where the viewers may express their opinions on various subjects. Similar opportunities are provided by internet forums that accompany both the website as well as particular broadcasts on the platform Player.pl.

The presence of the programs in numerous places as well as their focus on interactivity with the viewer make TVN Style's shows more like a stage described by Joan Kristin Bleicher (2010). In this model it is the viewer who decides on his or her own lineup and, in a more or less advanced way, enters a relationship with the television text (Bleicher 2010: 520). Moreover, the text itself does not always play the main role here - its fragment placed on a Facebook timeline is not only detached from the lineup but also, in a way, from the whole program/series and works as a separate recording, the aim of which is to engage the viewer. Controversial words taken out of context, shocking pictures or ambiguous quotations excellently fulfill this role. Many web surfers taking part in the discussions express their opinions on the basis of the 1- or 2-minute long fragment, which is confirmed by frequent enquiries where the whole program may be watched. Metamorphoses on makeover shows are especially popular, thus it appears justified to provide the most important theories concerning this genre.

The popularity of makeover shows is connected with the notion of "lifestyle" (Lewis), which, first, has become very popular in the contemporary culture and, second, in many aspects has begun to refer to creation of the "self" - the creation of one's own unique identity that will stand out but also, most importantly, attract attention. Moreover, "the new self" may be acquired through new clothes, a new car or occupation: "Lifestyle television, and in particular the makeover show, thus extends the DIY rubric to every aspects in one's life from home décor to selfhood" (Lewis 2009: 3). Regardless of the main subject, it does so in a similar way, in accordance with a virtually identical pattern. Tania Lewis (2009: 2) mentions a few features of makeover shows, which, de facto, may be reduced to generic indicators. At the beginning the chosen person is surprised by the expert visiting him or her at home or workplace. Then the expert starts a conversation and shows what mistakes the protagonist of the episode makes: mistakes in his or her nutrition, attire, work or, generally, lifestyle. Polish researcher Małgorzata Lisowska-Magdziarz (2012: 31-32) emphasizes that the stage of confrontation with the revealed situation is connected with a public confession - frequently, in a way, being an admission of the problem and guilt. It is accompanied by strong emotions - the protagonist discovers as well as reveals before the viewers his or her weaknesses. The greater, the more visible and moving they are, the more visible is the power of television:

"The exposition is also recognition of the power of media. This is why the master of metamorphosis at this stage frequently emphasizes the need for complete trust and submission on the part of the transformed person, entrusting his or her own privacy and future because at this moment the third stage begins: 3) rejection of the old "me" [own 
translation - A.P.] (Lisowska-Magdziarz 2012: 32).

The categorical separation from the person that one used to be is necessary and confirms the protagonist's readiness for transformation. After this part the actual change takes place, the course of which is supervised by the expert, and, finally, the public reveal occurs (Lewis 2009: 3).

Jack Z. Bratich (2007: 8), on the other hand, considering makeover shows in the category of reality television, notes that transformation turns ordinary people into celebrities and celebrities - into ordinary people. The process is visible not only in the narrative and esthetic structure of the program itself. It gains even more significance in social media,where the protagonist of the makeover show appears and, most importantly, is assessed like a star, while wellknown people are treated like friends with similar problems. This engagement makes transformations even more spectacular and visible. They are discussed not only by people in the studio or viewers in front of the TV, but also hundreds of web surfers expressing their opinions on internet forums. And, what is more, it is their opinions that will reach other users, who will engage in the conversation, and, as a result, become interested in a program that they have not watched before. Frequently the burden of attention is transferred from the protagonist himself or herself to the expert that supervises the transformation. He or she becomes not just a celebrity but an idol. Trinny and Susannah or Gok Wan are well-known people believed to be authorities on their fields. However, the question of understanding the term "authority" is controversial. One may speak here of the celebrity cult, which Zygmunt Bauman (2008: 204-205) calls "idolatry" influencing the life politics of an individual to a greater and greater degree. Idols, just as the transformations themselves, are not permanent - they last as long as they are talked about and shown. Therefore, the task of the contemporary viewer is to remain in the circle of newer and newer transformations and their masters, although this does not have to be an unreflexive or even thoughtless pursuit. As Katherine Sender's research (2012) shows, to many people makeover shows provide an inspiration with simultaneous awareness of the introduced manipulative procedures. The author uses the notions of "reflexivity" and "reflexive self" in the description and examination of the genre:

"(...) reflexivity describes how makeover shows rework ideas about the self through the particular demands of contemporary television programming. These shows mobilize audiences' reflexive engagements with the text, their viewing habits, their social relations and their ideas about themselves as projects to be worked on" (Sender 2012: 4).

This approach is confirmed also by the users' opinions posted on TVN Style's fanpage, which will be elaborated upon in the further part of the article. However, what is worth noting in Sender's approach is the reference to other researchers (Ooullette 2004; Ooullette and Hay 2008) recalling Michel Foucault and his concept of "governmentality" in the context of reality shows. Television programs become implementations of the technology of power, especially of what the French philosopher calls "technologies of the self" (Foucault 1998) and relates to the process of change and creation of oneself in order to be happy. In this context, makeover shows indicate the directions of change but also control and supervise it: "(...) makeover shows both encourage audiences to view candidates with contempt and to reform themselves in order to avoid such contempt from others" (Sender 2012: 8-9). Thus so many programs focus on the metamorphosis of the looks through weight loss, changing hairstyles and clothes - in this way not only does a person emphasize his or her individuality (which, in reality, is just an appearance), but also fits into current trends, including market mechanisms. At the basis of change there is always consumption and this is what makes the consumption of media, especially entertainment programs, pleasurable - the more pleasurable the greater the possibility of expressing one's own opinion or sharing one's own stories by the viewers. Protagonists of the shows are selected so that the viewer may relate to them and apply appropriate changes in his or her own life. Małgorzata Bogunia-Borowska (2012) notes that in Poland change gains even more importance. The author emphasizes the role of television in propagating changes as a new way of living after the 1989 political transformation, when Poland became a democratic country. Similarly - just as the abovementioned researchers - Bogunia-Borowska writes that the omnipresent affirmation of transformation in every aspect of life is actually a tool of control that does not encourage people to take active part in the social life but provides "information about the need to conform with a specified way of being and acting" [own translation - A.P.] (BoguniaBorowska 2012: 153). Similarly, the possibility of expressing their opinions may not equal the users' actual freedom of speech and choice but be reduced to gaining much more control by the media over the viewers by learning what they do or do not like.

Finally, one should also note that women's television largely maintains stereotypes about this sex. Any metamorphoses that are to "return" self-esteem to the woman actually push her back into the canon of what is accepted as "beautiful" or "womanly" in the consumption culture. Programs pertaining to, for instance, professional fulfilment, are in minority. If one looks at TVN Style's lineup, he or she may feel that a woman, first and foremost, should know how to 
apply make-up ("The Beauty Clinic" - original title: "Klinika urody"), dress up ("Style Magazine" - "Stylowy Magazyn," "Sablewska's Way with Fashion" - "Sablewskiej sposób na modę"), clean the house ("The Perfect Housewife" "Perfekcyjna Pani Domu"), raise her child or, finally, cook a delicious meal ("Delicious 25"- "Pyszne 25"). Moreover, nearly all of the programs contain product placements, in accordance with the notion that women are the best consumers. And although they do not have to be just housewives anymore, still, many reflections of Betty Friedan's (2012) contained in her book The Feminine Mystique remain valid.

\section{Methodology}

The conclusions presented in the article have been drawn on the basis of the analysis of the content of posts and comments published on TVN Style's fanpage between November 10 and December 3, 20141. Overall, 60 posts and 794 comments were coded, which is a justified number due to the repetitive character of the published content, depending largely on the lineup of the channel. The posts published by the station were analyzed in two categories: autoreferential and engaging. The first one refers to the degree to which television refers to itself through new media. The other one specifies the content that is not related to the programs but aiming at an increase in the activity of the users and at engaging them in a discussion. Further analysis took into consideration all comments accompanying the posts viewed with use of the standard function "Top comments" provided automatically by the Facebook interface. The comments have been ascribed with the following codes:

- Positive opinion about the show or its participants - a message expressed usually by means of simple statements such as "I like this show," "I love the host" or positive emojis;

- Critical opinion about the show or its participants - a message expressing a negative attitude toward the program or its hosts/protagonists;

- Discussion - problem messages provoking other users to express their opinions with a clear indication of one's own belief;

- Own story - comments in which the users tell their own stories analogical to the main post and the problem touched upon in the post;

- Information - requests for details about a particular show pertaining to more technical issues than the content of the broadcast itself (e.g. questions about the time of broadcasting, possibility of viewing the program via the internet, the brand of clothes worn by the host);

- Simple interaction - answers to the question contained in the post, which simultaneously are not opinions about the program nor do they start a discussion;

- Hate - vulgar comments;

- Spam - advertising and promotional messages or ones that do not relate to the current discussion or the content of the main post in any way;

- Other - posts that do not classify as any of the abovementioned categories.

The coding categories have allowed for specification of the degree to which the content published on the fanpage is engaging and arouses an actual interest in given television content, at the same time broadening the reach of the station. The analysis of particular posts shows which of them are more interesting to the users as well as in what way the discussions are held or, above all, to what degree the published comments create discussions or remain simple opinions. Moreover, the conducted research indicates to what extent the users approach the broadcasted programs and topics touched upon in them critically.

\footnotetext{
${ }^{1}$ All the presented quotations of users' comments and descriptions of particular posts come from the abovementioned fanpage, which is available at: https://www.facebook.com/tvnstylepl?fref=ts. The names of particular shows have been translated to English because they unambiguously indicate the subject of each program and help understand the whole text.
} 
Graph 1. The identity of the author of a comment

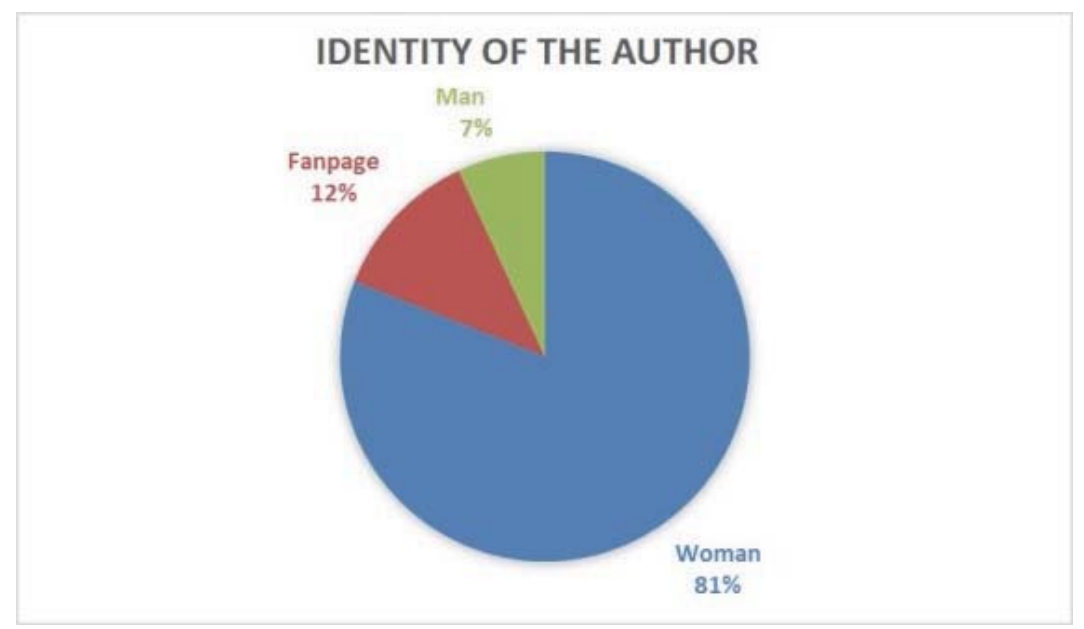

Graph 2. The type of comment

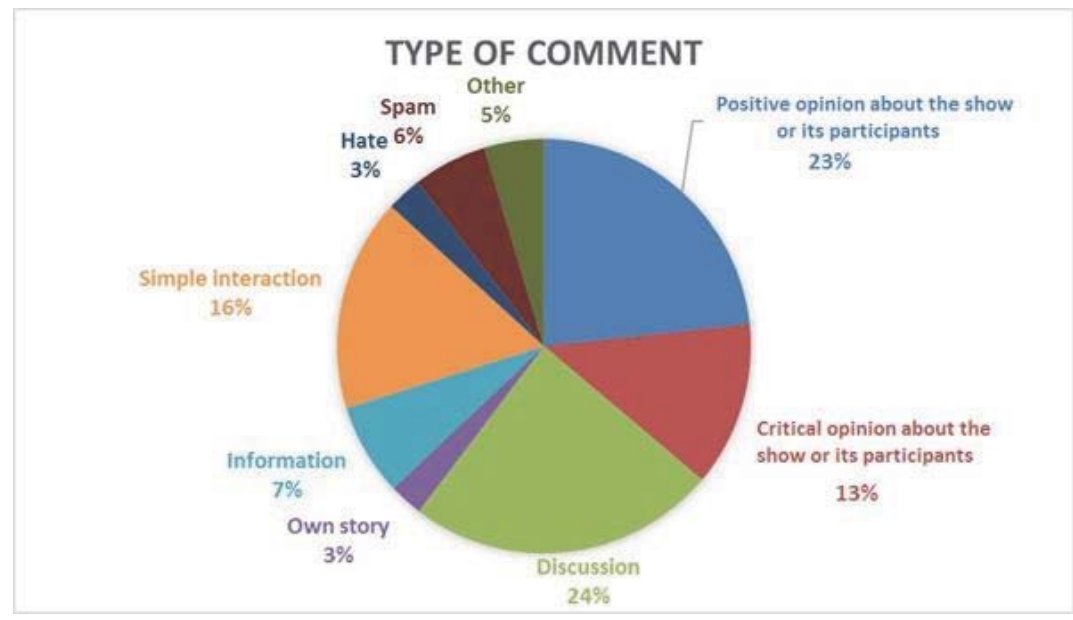

\section{Television for Women - A Fanpage for Women?}

Among the 794 comments most of them, 643, were written by women, the authors of 55 were men and 96 messages were written by official profiles (fanpages of various companies) or profiles in the case of which it was impossible to determine the sex of the author on the basis of the picture and the name given (graph 1). In accordance with the station's assumptions, the television fanpage engages women, that is the main target group, the most. Among the messages the majority are ones creating discussions (192), being positive (185) or negative (102) opinions on the program or simple interactions in response to the question asked by the administrator (graph 2). However, it is worth mentioning that the statistics are exaggerated by a few posts that were the most popular and by the analysis of which one may simultaneously note a few characteristic features of grassroots narration occurring around television. Discussions started usually in the case of linking makeover shows but also talk shows that touched upon topics controversial due to cultural relations in Poland. Such an example may be a trailer of "The City of Women," in which the hosts addressed the topic of catholic pre-marital courses or contraception. This is a subject that for years has aroused controversies in Poland because the Catholic Church has a strong position in the country. Another post that provoked a discussion was one about a book and an idea of introducing a diet in which, for instance, one would not eat meat on Mondays. This is an interesting example of how a post on healthy food provoked a discussion on the worldview and religion, as it is accepted that Catholics do not eat meat on Fridays: 
B: You can add Monday to your meat-free Friday and it will be even healthier and more interesting. I assure you that the authors of the book didn't mean to disturb anyone's tradition.

C: Isn't Friday enough? I've heard ever since my childhood that Friday is the day of fasting, without any meat. D: Have you been instilled with the faith, too, or is it just a conviction?

C: Unfortunately, no one succeeded in that... I eat meat whenever I like and, as for faith, it depends. I definitely am not perceived positively by Catholics because I go to church whenever I want to and I believe in what I want to believe. I belong to non-practicing believers, I guess that's what they're called...

Not only do makeover shows arouse discussions, but they also provoke viewers to talk about their own stories and broaden the narration with new sub-plots. Elisabeth Evans (2011: 1-2), analyzing the contemporary television and recalling Jenkins, writes about "transmedia storytelling" and "transmedia distribution" that need to be understood as narration composed of numerous texts and exceeding a single medium. Referring to this concept, stories described by the users, which, on the one hand, may be understood as extension of the program's plot, and, on the other hand, being an unambiguous reply to television content in the space outside television, may be called true storytelling. The true experiences of the users complement the story of the program's protagonist, confirm his or her struggles and, above all, make it close to "ordinary people". Moreover, they reinforce the status of the program itself, in accordance with the notion that "we really need such shows because many people struggle with similar problems". True storytelling also reveals the strength of the program, which provokes the users to describe their own experiences, which, on the other hand, shows strong engagement in the texts. Under a post referring to the program "Life without Shame" (original title: "Życie bez wstydu"), where a woman struggling with excess skin after losing $50 \mathrm{~kg}$ was shown, the following comments appeared:

\section{A: Exactly as if someone was telling the story of my childhood...}

B: (...) I've also heard that I'm too fat, that I should lose weight. I too used to torture myself with exercise but then I told myself that I wouldn't do as others wanted me to just to please them (...).

Honest confessions as well as the story told in the program usually make the commenters become a support group. It is hard to speak here of a virtual community, as it is rare for web surfers to establish any personal relationships, although one may say that the users fulfill the role of friends and family in the studio, who, first, support the participant and, second, witness a spectacular transformation:

A: Congrats! I admire your perseverance, you've achieved a lot. Losing so much weight is a great challenge... Keep your head up, now it's gonna be better than you think. You just need to smile a lot because you're a pretty girl. Keep warm.

Among the positive opinions pertaining to the programs messages concerning Gok Wan, a well-known stylist specializing in metamorphoses, dominated. Under his picture with the words "Hello, smile" 35 positive opinions expressed mainly through emoticons and messages such as "Gok is amazing", "I love his shows", "Gok is so nice", etc. appeared. A similar number (30 positive messages) were published under a post announcing a program featuring the stylist. This is an example of a celebrity that definitely wins the liking of social media users. Much engagement was also aroused by posts in which the station wished to learn its fans' opinions. In the first one the best metamorphosis was to be chosen and the second one was a simple question about the users' plans for St. Andrew's Day on November 30, that is on the name day of Andrew (Andrzej), on which in Poland usually meetings to play fortunetelling games with friends are organized. What is important, it was the only post, which, for 60 posts, did not redirect in any way to the station or news related to it. Posts that do not require lengthy responses from the users or any knowledge of the programs aim at building their engagement and, above all, at "stimulating" web surfers that usually do not take part in discussions. In this way the station shows that it wishes to start a dialog with the viewers.

TVN Style's television fanpage is also a place where the viewers may express criticism toward the station or even reveal the mechanism of media manipulation and the structure of some shows. The reason for such actions was, for instance, a trailer of the program "The Perfect Nanny" (original title: "Idealna niania"), in which a candidate for a babysitter discovers that in the house of her potential employers hidden cameras have been installed and that she is being observed by the parents. Alongside critical opinions on the idea of the program there were also messages stating that the show was scripted and that extras appearing there had also been seen in other programs. One of the discussions pertained to the format and license of the production and proved that the stories that were supposed to be true were actually based on a scenario:

A: Scripted just like any other shows this kind. And the best thing is that the program "Why me" [original title: "Dlaczego 
ja"] reflects other foreign shows. I live in Germany and when I watch the Polish one I know what will happen because it was aired here a year ago. The same topic, just presented in a different way (...).

B: Those are licensed shows (...).

It arises from the above that viewers and users are aware of television manipulations, however, they are critical toward them only in the case of shows that are generally not appreciated. Such discussions did not appear in the context of trailers of shows where popular celebrities, such as Gok Wan, appeared. The person of the host is then, in a way, a catalyst of negative emotions.

At the end one should note that TVN Style's fanpage had, on January 3, 2015, 204,373 fans. From the conducted research it arises that, on average, for 60 posts there were 13 comments. The numbers show relatively little engagement of the viewers in the created narration. Interest is aroused by controversial topics or posts presenting metamorphoses and their authors. The fanpage does not fulfill the role of a forum or magazine for women. It probably stems from the fact that $99 \%$ of the posts refer to the lineup - there are few posts that exceed references to the station and reflect current communication trends in social media. Narration structured in this way, however, leads to the conclusion that television for women has been dominated by makeover shows and the culture of celebrities, while assessing, comparing and evaluating have become the dominant forms of reflection on reception.

\section{Conclusions}

In conclusion, metamorphoses and their experts are the topics that arouse the most interest among the users of TVN Style's fanpage. The most popular form of expression are discussions, in which the web surfers tell their own stories or express opinions supported by their experiences. From the conducted analysis it arises that through the selection of the published content the station emphasizes the importance of physical appearance in the contemporary culture. This interest in metamorphoses is caused also by sheer curiosity, the willingness to express opinions and to peep, that is features that excellently describe the culture of transparency. Lisowska-Magdziarz (2012: 44-48) writes that media have become its main tool. As the researcher emphasizes, the culture of transparency, on the one hand, consists in revealing and showing the problem and, on the other hand, in removing any barriers that could inhibit this process. The effect is the more spectacular the more the topic touched upon belongs to the taboo. Hence the growing popularity of makeover shows, in which the participants reveal their shameful problems and undergo, for instance, plastic surgeries. Breaking a taboo, however, remains within some limits, as the programs "still need to confirm the existing status quo, with its hierarchy of values, esthetic and communication principles, regulating the social functioning of individuals and groups as well as the assumption of the positive role of the medium" [own translation - A.P.] (Lisowska-Magdziarz 2012: 52). However, the notion of transparency gains new importance in relation to television and its new media environment. The users, by means of their messages, may reveal things that were meant by the station to remain secret, such as the stages of production, because a given web surfer had an occasion to observe or take part in them. And, what is important, it is not about the so-called making of, which serves to keep up the appearances of full transparency and the "fact" that television does not hide anything and the program is fully authentic (Lisowska-Magdziarz 2012: 55-56). Actions performed by the users are uncontrollable (although posts can be moderated by the administrator of the fanpage after publication) and may definitely be subversive. In this way actions performed by television may become even more transparent than would arise from the assumption of the station itself. Moreover, there may always be a situation in which a comment will appear that is an interpretation not compliant with the broadcaster's intention or that will provoke a discussion on a completely different, controversial topic. The conducted research shows, however, that in case of the Polish station aimed at women the level of tele-participation, using Sharon Marie Ross's term (2009), describing a situation when "(...) the Internet has become a site for tele-participation that opens up for viewers and creators myriad ways in which to experience watching and making TV" (Ross 2009: 4), is still at its beginning. In contrast with the initial hypothesis, women are not a very active group on the television fanpage. On the other hand, however, the station itself does not create texts aimed specially at the users of social media. Moreover, as long as the official profile of the station refers to the lineup, rarely do the programs themselves encourage the viewers to be active on the profiles accompanying the shows. Still, the most popular form of expressing one's engagement is clicking the "Like it" button under a given link.

\section{References}

Bauman, Z. (2008). "Świat z Telewizją, Świat w Telewizji". In: M. Halawa, P. Wróbel (eds.), Bauman o popkulturze. Wypisy (p. 186-215). Warsaw: Wydawnictwa Akademickie i Profesjonalne. 
Bleicher, J.K. (2010). "Nowe telewizje, nowe programy, nowe formy? Funkcje paratekstów w telewizji internetowej”. In: A. Gwóźdź (ed.), Pogranicza Audiowizualności. Parateksty kina, telewizji i nowych mediów (p. 513-532). Cracow: Universitas.

Bogunia-Borowska, M. (2012). Fenomen Telewizji. Interpretacje Socjologiczne i Kulturowe. Cracow: Wydawnictwo Uniwersytetu Jagiellońskiego.

Bratich, J. Z. (2007). "Programming Reality. Control Societies, New Subjects and the Powers of Transformation". In: D. Heller (ed.), Makeover Television. Realities Remodelled (p. 6-22). New York: I.B. Tauris \& Co Ltd.

Evans, E. (2011). Transmedia Television: Audiences, New Media and Daily Life. New York: Routledge.

Foucault, M. (1988). "Technolgies of the Self". In: L. H. Martin, H. Gutman, P. H. Hutton (eds.), Technologies of the Self. A Seminar with Michel Foucault (p. 16-49). London: Tavistock Publications.

Friedan, B. (2012). The Feminine Mystique. Warsaw: Wydawnictwo Czarna Owca.

Krzysztofek, K. (2010). "Paratekst jako postfabrykant kultury". In: A. Gwóźdź (ed.), Pogranicza Audiowizualności. Parateksty kina, telewizji i nowych mediów (p.13-33). Cracow: Universitas.

Lewis, T. (2009). "Introduction: Revealing the Makeover Show". In: T. Lewis (ed.), TV Transformations. Revealing the Makeover Show (p. 1-7). London and New York: Routledge.

Lisowska-Magdziarz, M. (2012). Feniksy, Łabędzie, Motyle. Media i Kultura Transformacji. Cracow: Wydawnictwo Uniwersytetu Jagiellońskiego.

Lotz, A. D. (2006). Redesigning Women. Television after the Network Era. Urbana and Chicago: University of Illinois Press.

Michalska, J., Nowacka, B. (2014). "Media społecznościowe na Letniej Akademii Kongresu Kobiet", source: http://www.kongreskobiet.pl/ pl-PL/news/show/media_spolecznosciowe_na_letniej_akademii_kongresu_kobiet.

Ross, S.M. (2009). Beyond the Box. Television and the Internet. Malden: Blackwell Publishing.

Sender, K. (2012). The Makeover. Reality Television and Reflexive Audiences. New York and London: New York University Press. 